\title{
Semen-induced ovulation in the bactrian camel (Camelus bactrianus)
}

\author{
B. X. Chen, Z. X. Yuen* and G. W. Pan \\ Department of Veterinary Medicine, Gansu Agricultural University, Wuwei, Gansu and \\ ${ }^{*}$ Haixi Institute of Animal Science, Qinghai, People's Republic of China
}

\begin{abstract}
Summary. Bactrian camels $(63 \circ \circ, 8 \sigma \sigma)$ were used in the breeding season to determine the factors that will induce ovulation. After insemination of semen samples into the vagina, the ovaries were checked for ovulation by rectal palpation. The results indicated that ovulation was induced by the seminal plasma, but not by the spermatozoa, and the incidence of ovulation after insemination was $87 \%$. Most of the females $(66 \%)$ had ovulated by $36 \mathrm{~h}$ after insemination and the rest by $48 \mathrm{~h}$, as after natural service. The least amount of semen required to elicit ovulation was about 1.0 $\mathrm{ml}$. Intramuscular injections of LH, hCG and LHRH also caused ovulation, even in females that had not ovulated in response to insemination.
\end{abstract}

\section{Introduction}

Female bactrian camels are normally sexually mature at 3 years of age, but mating is usually allowed only when they are 4 years old, and they may continue to breed until at least 20 years of age. They are seasonal breeders, and the breeding season is from the end of December, when the daylight starts to lengthen and the temperature is low, to mid-April in China. Novoa (1970) showed that sexual activity in camelids appeared to be acyclic; the females did not have oestrous cycles comparable to those of spontaneous ovulators. Chen, Yuen, Kang \& Ge (1980) indicated that female bactrian camels exhibited follicular cycles, the follicles developing and regressing one by one. It took $19 \cdot 10 \pm 4 \cdot 25$ days from the start of development of a follicle $(\sim 0.5 \mathrm{~cm}$ in diameter) to the beginning of its regression. One mature or developing follicle was usually present in an ovary. When not allowed to mate, the camel manifested prolonged periods of oestrus; if mating occurred, then ovulation would take place $30-48 \mathrm{~h}$ later. The bactrian camel, the dromedary (Camelus dromedarius), the alpaca (Lama pacos) and the llama (Lama glama) are all induced ovulators. However, unlike the rabbit and cat, there is little information on the triggering mechanism of ovulation in the camel. Shalash \& Nawito (1964) suggested that copulation, mechanical or electrical stimulation of the cervix and other afferent stimuli would be necessary for ovulation in the dromedary. San Martin et al. (1968) reported that ovulation in alpaca was induced by coitus, and that follicles ovulated $26 \mathrm{~h}$ after coital stimulation or $24 \mathrm{~h}$ after intravenous injection of hCG. Fernandez-Baca, Madden \& Novoa (1970) indicated that mounting accompanied by intromission was necessary to provide adequate stimulation for $\mathrm{LH}$ release and subsequent ovulation in alpaca. Musa \& Abusineina (1978) showed that ovulation in the dromedary was not spontaneous and required the stimulus of coitus, and that manual stimulation of the cervix did not induce ovulation. Chen, Yuen, Pan, Huang \& Gao (1983) reported that mounting and stimulation of the cervix with a rubber inseminating tube of the type used for horses or a long probe were not able to elicit ovulation in the bactrian; vaginal insemination did induce ovulation, but the numbers of animals were very small. The present study was therefore undertaken to investigate the ovulation-inducing effect of semen in bactrian camels. 


\section{Materials and Methods}

Animals and methods

The 63 breeding camels, 8-15 years of age, and 8 male camels, 4-10 years of age, were kept in different herds. The range was good and the camels grazed or browsed freely all year round, only a few of them were given supplementary food with $2 \mathrm{~kg}$ grain every evening in the winter months. The body weight of the female camels was about $480 \mathrm{~kg}$ and that of the males was about $600 \mathrm{~kg}$.

From the beginning of the breeding season, development of follicles was followed daily by rectal palpation. When the follicles had reached a diameter of $\geq 1.2 \mathrm{~cm}$, the females were treated with materials deposited intravaginally or by intramuscular injection of hormones. The ovaries were checked for ovulation by rectal palpation at 24,36 and $48 \mathrm{~h}$ after treatment.

\section{Intravaginal administration}

A rubber inseminating tube of the type used for horse AI, which was a product of the Chinese Animal Science and Veterinary Instruments $\mathrm{Co}$., was inserted gently and as deeply as possible into the vagina. The materials to be tested were injected through the tube by means of a syringe.

Whole semen. Semen of male camels was collected by means of an artificial vagina as used for cattle. The semen was used immediately or stored at 0 to $-10^{\circ} \mathrm{C}$ for different lengths of time. The semen was thawed and warmed to $37^{\circ} \mathrm{C}$ before use. The insemination volume was $0.5-7.0 \mathrm{ml}$. In 4 animals the semen was deposited in the uterus instead of the vagina.

Bull, goat and boar semen samples $(2-3 \mathrm{ml})$, stored in the refrigerator $\left(0\right.$ to $\left.-2^{\circ} \mathrm{C}\right)$, were also tested.

Seminal plasma. After collection, the semen was centrifuged $(500 \mathrm{~g})$. The supernatant was examined microscopically and when the sperm count was $<10000 / \mathrm{ml}$, the seminal plasma was used in a volume of $3 \mathrm{ml}$.

Washed spermatozoa of high concentration. After centrifugation of semen and removal of the supernatant, saline $(9 \mathrm{~g} \mathrm{NaCl} / 1)$ was added to the sediment and the suspension was recentrifuged. The procedure was repeated 3 times and the final pellet examined. The washed spermatozoa were used at a concentration of 4-7 $\times 10^{8} / \mathrm{ml}$ and an insemination volume of $3 \mathrm{ml}$.

Accessory sex gland secretions. Male 5 was vasectomized. Collection of semen started 6 days after operation and was repeated every 2 days until the 18 th day when the sperm count was $<10000 / \mathrm{ml}$ and the seminal fluid was considered to consist of the secretions of the ampullae, prostate glands, urethral glands and bulbourethral glands. The insemination volume was $3.5-4.0 \mathrm{ml}$ but on 3 occasions this male was allowed to mate naturally.

Skim milk. As control, skim milk from a cow was deposited into the vagina in a volume of $6 \mathrm{ml}$.

\section{Natural mating}

Male camels were allowed to copulate and 3-10 min after the end of coitus, the duration of which was about $3 \mathrm{~min}$, semen was flushed out of the vagina with saline.

\section{Exogenous hormones}

When ovulation did not occur in response to the intravaginal treatments (except for the control substance) hormones were injected i.m. to determine whether the materials were ineffective or the follicles were unable to ovulate. The hormones used were LH (Wuhan Biochem-Pharmaceutical Co., Hankow, China), 300 i.u. in $4 \mathrm{ml}$ saline; hCG (Tong-Feng Pharmaceutical Co., Beijing), $1000-2000$ i.u. in $4 \mathrm{ml}$ saline and LHRH analogue (Biochemical Institute, Shanghai), 250-500 $\mu \mathrm{g}$ in $2.4 \mathrm{ml}$ saline. 


\section{Results}

Ovulation-inducing effect of components of camel semen

Whole semen. Of 32 females inseminated with semen from Males 1, 2, 3, 5, 6, 7 or 8, $28(87.5 \%)$ ovulated. The least amount of semen required for inducing ovulation was about $1.0 \mathrm{ml}$. All 3 females inseminated with not more than $1.0 \mathrm{ml}$ semen $(0.1-0.2 \mathrm{ml}$ semen was left in the inseminating tube) ovulated but 2 females receiving $0.5 \mathrm{ml}$ semen did not. One semen sample stored at about $-10^{\circ} \mathrm{C}$ for 67 days was effective in inducing ovulation. The ovulation time was similar to that after natural service, with $25(65 \cdot 8 \%)$ females having ovulated by $36 \mathrm{~h}$ and 13 by $48 \mathrm{~h}$.

There was no difference in the effect on ovulation when the semen samples were fresh and contained live spermatozoa (11/12 ovulating) or had been frozen at $-10^{\circ} \mathrm{C}$ for several days and contained dead spermatozoa ( $9 / 10$ ovulating).

Seminal plasma. Of 8 females inseminated, 6 ovulated.

Washed spermatozoa. None of the 7 females inseminated with washed spermatozoa of high concentration ovulated.

Accessory sex gland secretions. Of 7 females inseminated (including 3 natural services by the vasectomized male), all ovulated.

Control substance. None of the 7 females tested with skim milk ovulated.

Natural service followed by flushing of the vagina

Of 4 females tested, 3 did not ovulate and 1 ovulated.

\section{Effect of bull, goat and boar semen}

Of 7 females inseminated with bull semen, 2 had ovulated by $36 \mathrm{~h}$ and 3 by $48 \mathrm{~h}$. One of the semen samples had been stored at 0 to $-10^{\circ} \mathrm{C}$ for more than 40 days. Five females inseminated with goat semen and 3 with boar semen did not ovulate.

\section{Ovulation-inducing effect of semen of individual male camels}

In this part of the study 8 male camels were used, and the effect of their semen on ovulation is summarized in Table 1.

Camel 4 appeared different from the others in that fewer females ovulated in response to its semen. Cystic follicles were detected in the ovaries of 3 of the females treated with semen of this male. Four females that had not ovulated in response to Male 4 did ovulate in response to hCG or LHRH injection, indicating that the follciles were able to ovulate.

Table 1. Ovulation-inducing effect of individual male camels

\begin{tabular}{cccccc}
\hline & \multicolumn{2}{c}{ Insemination } & \multicolumn{3}{c}{ Mating } \\
\cline { 2 - 4 } \cline { 5 - 6 } Male & $\begin{array}{c}\text { No. of females } \\
\text { tested }\end{array}$ & No. ovulating & $\begin{array}{c}\text { No. of females } \\
\text { tested }\end{array}$ & No. ovulating \\
\hline 1 & 3 & 2 & - & - \\
2 & 17 & 15 & - & - \\
3 & 4 & 4 & - & 2 \\
4 & 18 & 6 & 6 & 6 \\
5 & 13 & 12 & 6 & 1 \\
6 & 4 & 3 & 1 & - \\
7 & 4 & 3 & 1 & - \\
\hline
\end{tabular}


Reaction of individual female camels to semen

Of the 63 female camels investigated 4 showed abnormal ovulatory responses. One female suffered from chronic cervicitis, and another had cystic ovaries after insemination with semen of fertile male camels in two successive seasons. The other 2 females did not ovulate in response to insemination, but did after injections of hCG; moreover, other female camels had reacted to semen of the same male and ovulated.

\section{Ovulation-inducing effect of some reproductive hormones}

The results of i.m. injection of hormones are summarized in Table 2. The interval between injection and ovulation in all cases was $36 \mathrm{~h}$ except for one female in the $\mathrm{hCG}$ group for which it was $48 \mathrm{~h}$.

Table 2. Ovulation-inducing effect of reproductive hormones

\begin{tabular}{cccc}
\hline Hormone & Dose & $\begin{array}{c}\text { No. of females } \\
\text { tested }\end{array}$ & No. ovulating \\
\hline LH & 300 i.u. & 3 & 3 \\
LHRH & $250 \mu \mathrm{g}$ & 4 & 4 \\
& $500 \mu \mathrm{g}$ & 4 & 3 \\
hCG & 1000 i.u. & 1 & 1 \\
& 1500 i.u. & 3 & 3 \\
& 2000 i.u. & 2 & 1 \\
\hline
\end{tabular}

\section{Discussion}

The present results show that ovulation in bactrian camels is not spontaneous and is induced by seminal plasma, even after storage at low temperature. The spermatozoa were not effective in inducing ovulation. Bull semen also seemed to contain the ovulation-inducing factor. Intramuscular injection of camel semen resulted in ovulation in a similar manner (unpublished data). However, the nature of the inducing factor and the mechanism of stimulation of LH release after its absorption remain to be clarified. The vagina or the uterus may be the place of absorption since intrauterine insemination of 4 females also led to ovulation. Absorption may be very rapid because 1 of 4 females ovulated after mating and then having the semen flushed from the vagina 3-10 min later.

In the present study ovulation occurred in $41 / 47(87 \%)$ camels after insemination although in our previous work (Chen et al., 1980) ovulation took place in all of the 26 females mated naturally. The mating behaviour might therefore have some augmentative effect on the semen-induced ovulation. There are also variations in the responses of individual females and in the ability of particular males to induce ovulation.

We thank the International Foundation for Science for financial assistance (Research Grant No. 462); and the Committee of Science and Technology, Institute of Animal Science and Camel Farm of Haixi Prefecture, Qinghai Province, for the necessary facilities.

\section{References}

Chen, B.X., Yuen, Z.X., Kang, C.L. \& Ge, Y.G. (1980) Reproductive pattern of the bactrian camel. Il. The sexual activities of the camel. Acta vet. zootech. sin. 11, 65-76. [In Chinese.] 
Chen, B.X., Yuen, Z.X., Pan, G.W., Huang, Y.M. \& Gao, Y.H. (1983) Studies on the ovulation mechanism in the bactrian camel. II. The role of semen in induction of ovulation. Acta vet. zootech. sin. 14, 161-166. [In Chinese.]

Fernandez-Baca, S., Madden, D.H.L. \& Novoa, C. (1970) Effect of different mating stimuli on induction of ovulation in the alpaca. J. Reprod. Fert. 22, 261-267.

Musa, B.E. \& Abusineina, M.B. (1978) The oestrous cycle of the camel (Camelus dromedarius). Vet. Rec. 103, 556-557.
Novoa, C. (1970) Reproduction in Camelidae. J. Reprod. Fert. 22, 3-20.

San-Martin, M., Copaira, M., Zunica, J., Rodreguez, R., Bustinza, G. \& Acosta, L. (1968) Aspects of reproduction in the alpaca. J. Reprod. Fert. 16, 395-399.

Shalash, M.R. \& Nawito, M. (1964) Some reproductive aspects in the female camel. Proc. 5th Int. Cong. Anim. Reprod. \& A.I., Trento 2, 263-267.

Received 22 June 1984 